\title{
Tween, プルロニック系活性剤水溶液の量点とェマルジョンの転相温度との関係
}

\author{
(踝和 39 年 10 月 21 日范里)
}

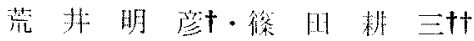

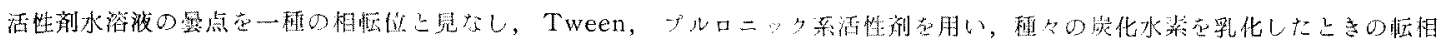

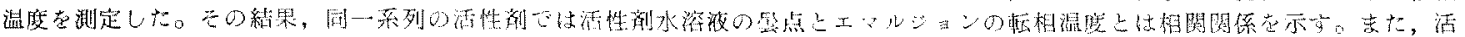

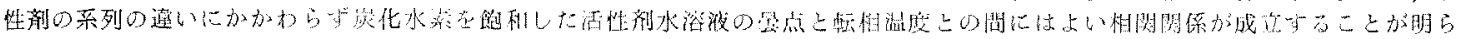

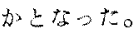

\section{1 緒言}

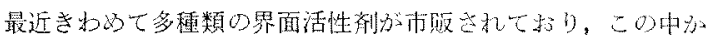

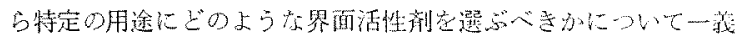

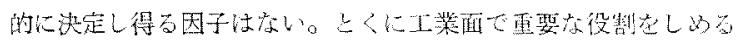

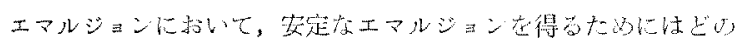

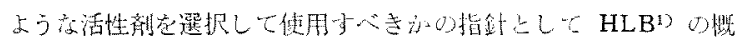

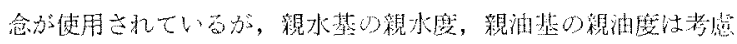

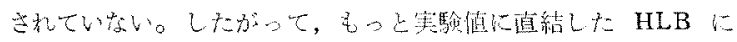

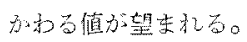

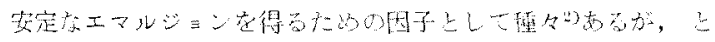

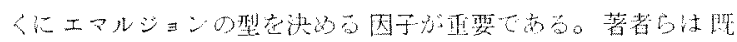

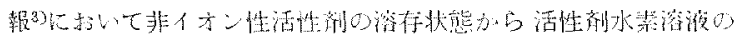

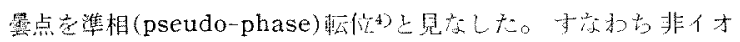

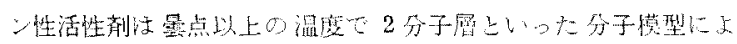

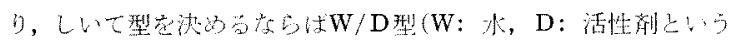

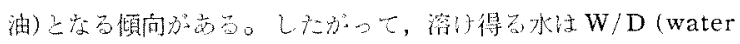

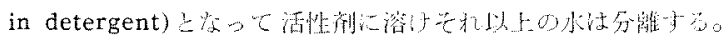

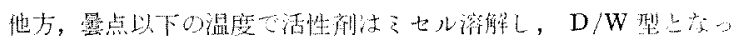

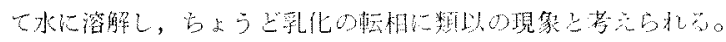

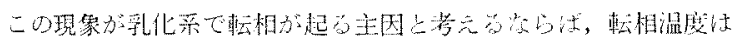

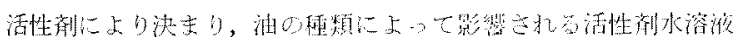

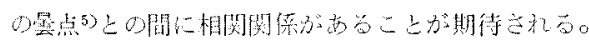

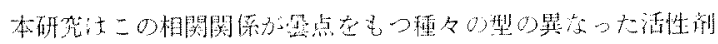

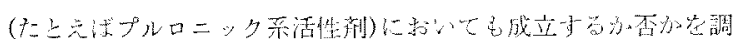

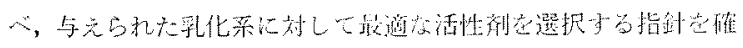
立与研究の一囬しして行なった。

\section{2 実験}

\section{1 試 料}

プルロニック系活性削 $\left(\mathrm{HO}\left(\mathrm{C}_{2} \mathrm{H}_{4} \mathrm{O}\right)_{a}\left(\mathrm{C}_{3} \mathrm{H}_{6} \mathrm{O}\right)_{6}\left(\mathrm{C}_{2} \mathrm{H}_{4} \mathrm{O}\right)_{6} \mathrm{H}\right)$ 之 してつぎ示可 Wyndotte Chemical Corp. 制品い 4 程類老用 vたo

$$
\text { プルロ =ッタL-44(分子背: 2000, } a+c / b=1 \text { ) }
$$$$
\text { ブルロ ンクL-62(打子胃: } 2000, a+c / b=0.3 \text { ) }
$$

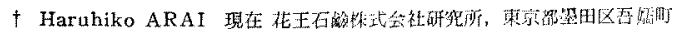

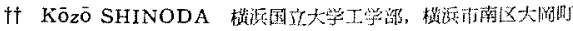

1) W. G. Griftin, J. Soc. Cosmetic Chemists 1, 311(1949).

2) P. Becher, "Emulsion; Theory and Practice" Reinhold Publish Co., New York(1957) p. 85.

3) K. Shinoda, H. Arai, J. Phys. Chem. B8, 3485(1064).

4) K. Shinoda, Bull. Chem. Soc. Japan 35, 1213(1962).

5) W. N. Maclay. J. Colloid Sci. 11, 272(1956).
ブルロンタL-64(分子期: $3000, a+c / b \div 1.1$ )

プルロニッタ $\mathrm{P}-66$ (分子禁: 不明)

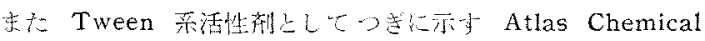

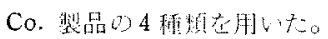

Tween 20(ホリオキシエチレンンルビタンもノうウレート)

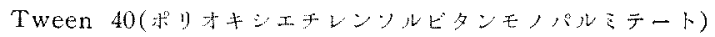

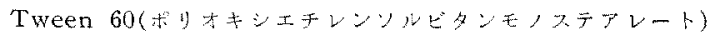

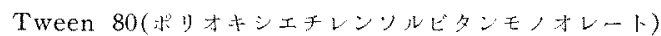

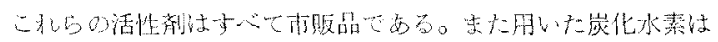

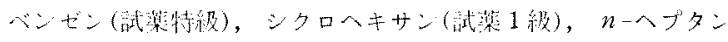

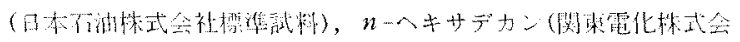

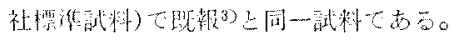

\section{2 実験方法}

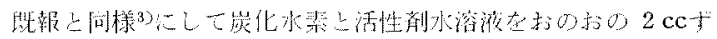

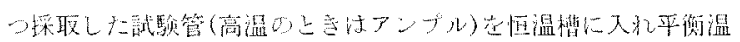

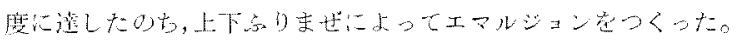

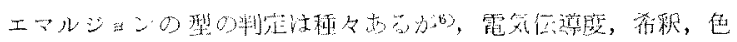

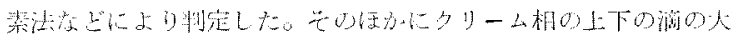

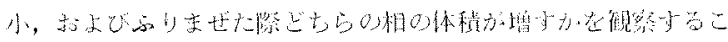

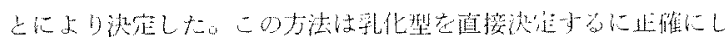

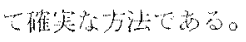

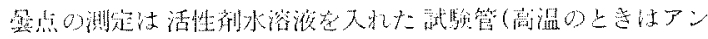

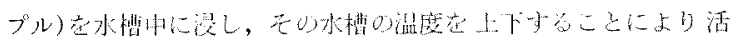

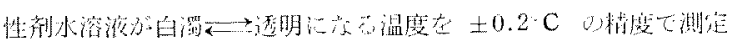

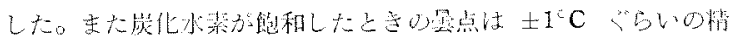

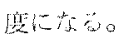

\section{3 結果扰よび考察}

\section{1 プルロニック系活性剂}

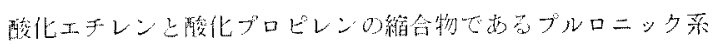
活州椡は $\mathrm{HO}\left(\mathrm{C}_{2} \mathrm{H}_{4} \mathrm{O}\right)_{a}\left(\mathrm{C}_{3} \mathrm{H}_{6} \mathrm{O}\right)_{b}\left(\mathrm{C}_{2} \mathrm{H}_{4} \mathrm{O}\right)_{c} \mathrm{H}$ の化学式大表b

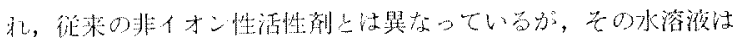

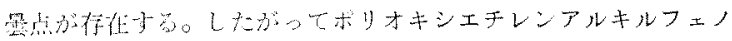

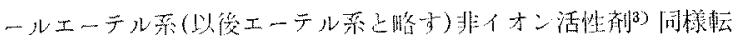
相韲度が存在ずることが期待される。

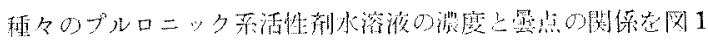
以柴した。

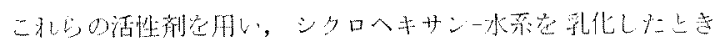

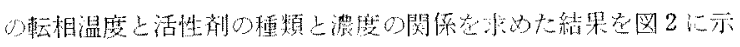
Lt:

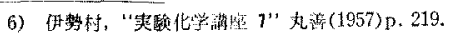




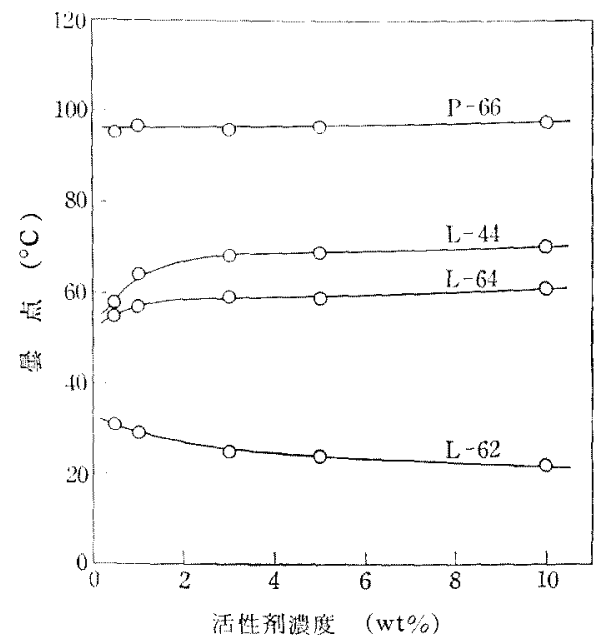

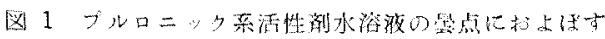

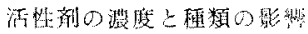

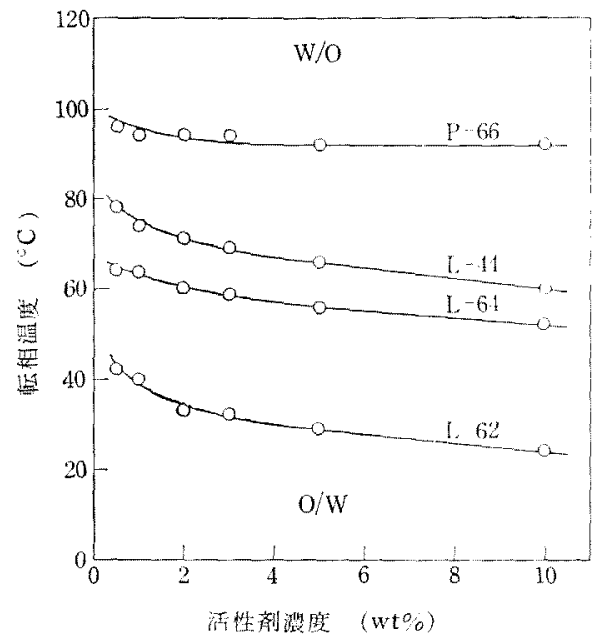

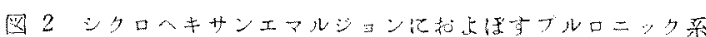

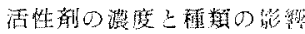

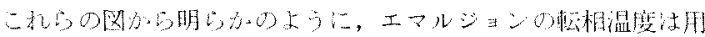

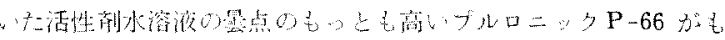

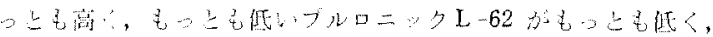

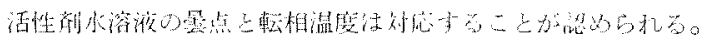

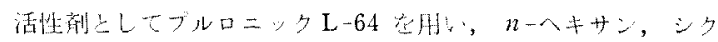

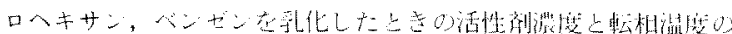

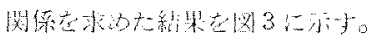

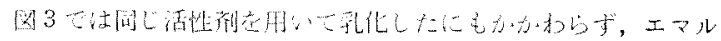

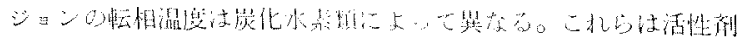

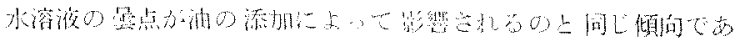

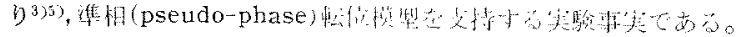

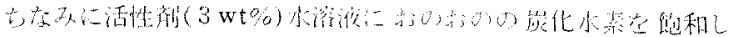

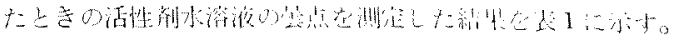

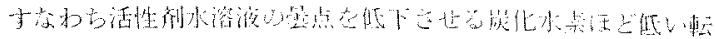

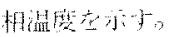

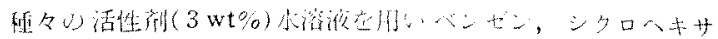

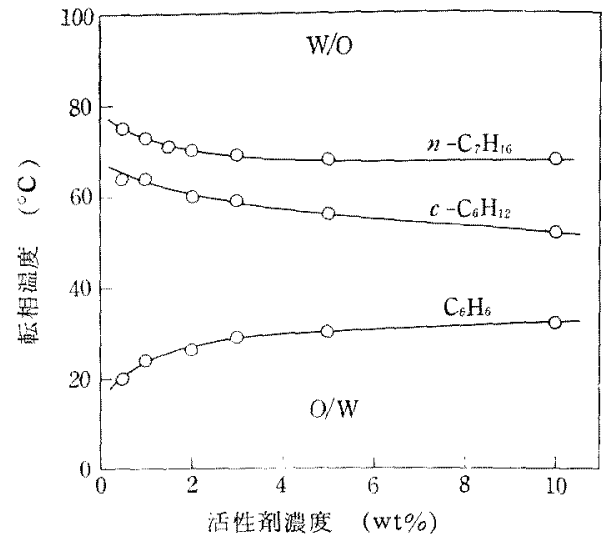

四 3 エルジンの标相温度に打上ぼすプルロニック

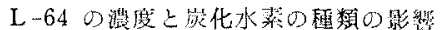

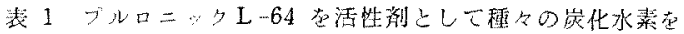

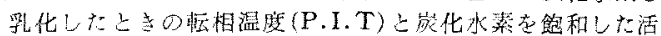

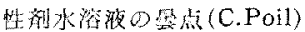

\begin{tabular}{|c|c|c|}
\hline 䓡化水类の種颣 & P.I.T $\left({ }^{\circ} \mathrm{C}\right)$ & C.Poil $\left({ }^{\circ} \mathrm{C}\right)$ \\
\hline$n-\infty \Rightarrow \Rightarrow$ & 79 & 47 \\
\hline シク口八未扩ン & 50 & 24 \\
\hline くンだ & 29 & $-a)$ \\
\hline $\mathrm{c}$ & - & 59 \\
\hline
\end{tabular}

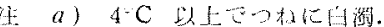

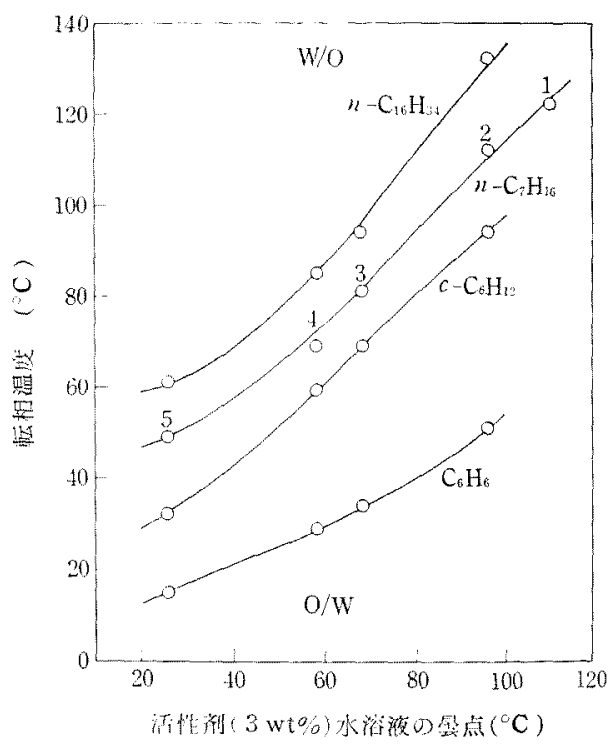

1: F-68, 2: P-66, 3: L-44, 4: L-64, 5: L-62

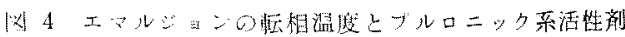

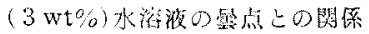

ン， nーヘプタン，nーヘキサデカンを乳化したとき忶相温度る

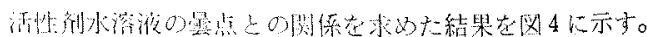

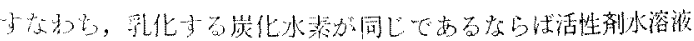

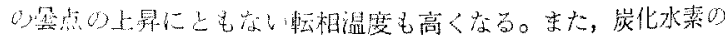

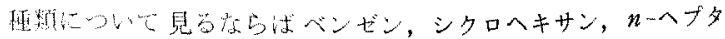

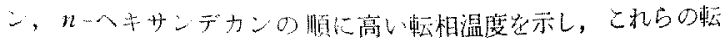




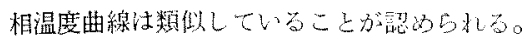

\subsection{Tween 系活性威}

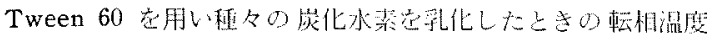

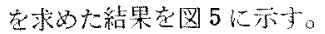

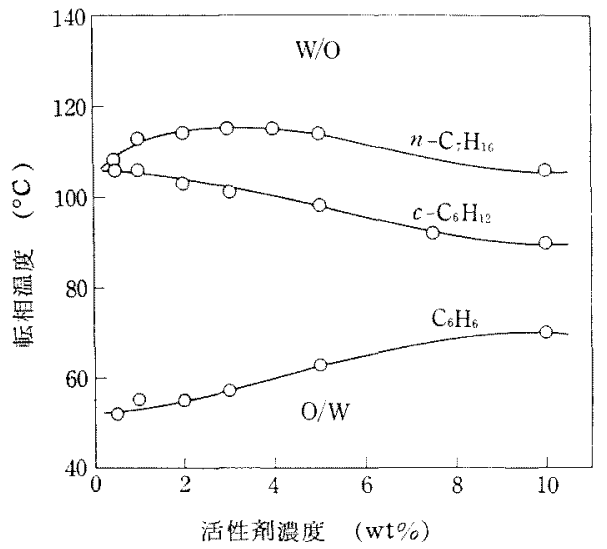

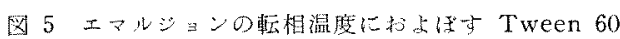

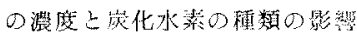

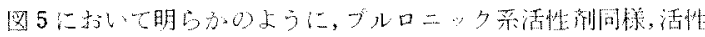

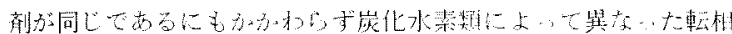

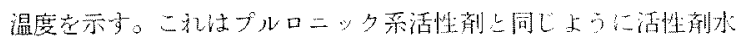

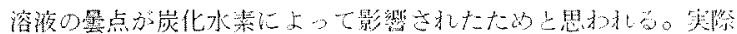

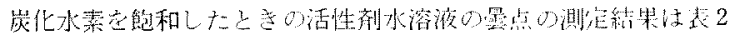

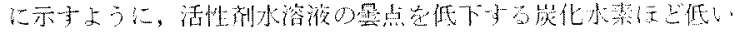

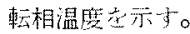

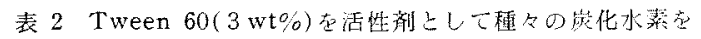

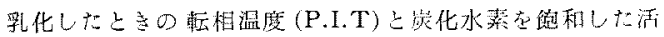

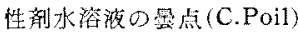

\begin{tabular}{|c|c|c|}
\hline 炭化水素の種租 & P.I.T $\left({ }^{\circ} \mathrm{C}\right)$ & C.Poil $\left({ }^{\circ} \mathrm{C}\right)$ \\
\hline$n-\rightarrow \Rightarrow=$ & 115 & 103.5 \\
\hline 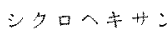 & 101 & 78.8 \\
\hline ベンゼ & 57 & $\ldots$ \\
\hline な & - & 83.5 \\
\hline
\end{tabular}

注 a) 4 C 以上厒.

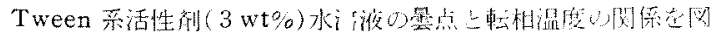

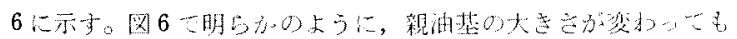

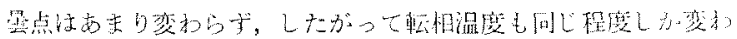
万て古い。

3.3 プルロニック系, Tween 系,エーテル菜3活性郕の共通性

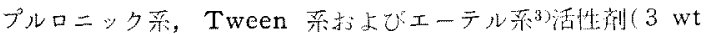

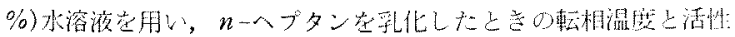
剂需点の關倸范四 7 に示す。

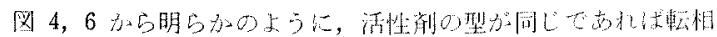

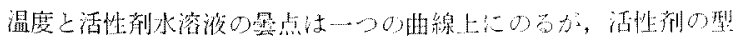

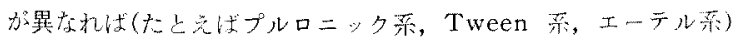

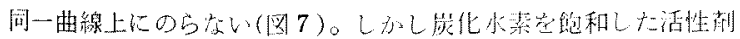

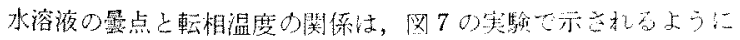

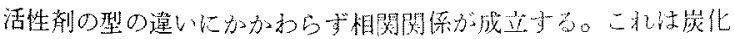

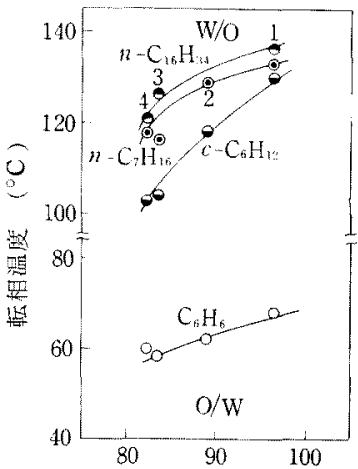

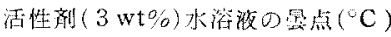

1: Tween 20, 2: Tween 40, 3: Tween 60, 4: Tween 80

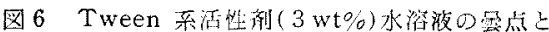
エマルションの枟相湿度との関原

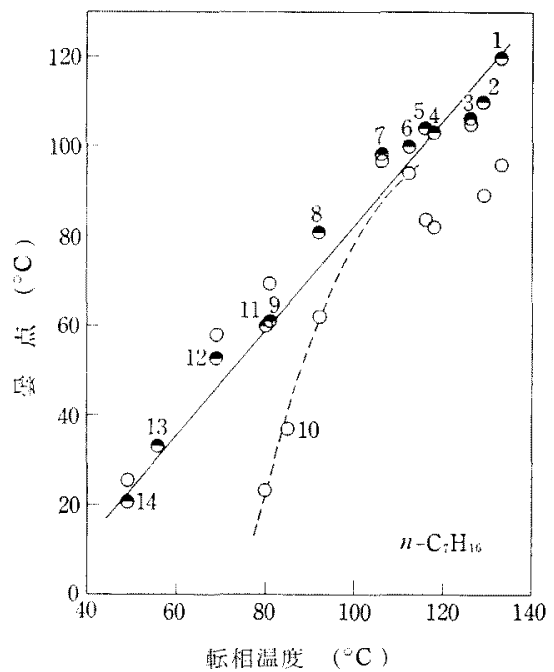

1: Tween 20, 2: Tween 40, 3: $\mathrm{R}_{9} \mathrm{C}_{6} \mathrm{H}_{4} \mathrm{O}\left(\mathrm{CH}_{2} \mathrm{CH} \mathrm{O}_{1 ; . ;} \mathrm{H}\right.$, 4: Tween 80, 5: Tween 60, 6: $\mathrm{R}_{9} \mathrm{C}_{6} \mathrm{H}_{4} \mathrm{O}\left(\mathrm{CH}_{2} \mathrm{CH}_{2} \mathrm{O}\right)_{14.0} \mathrm{H}$, 7: $\mathrm{R}_{22} \mathrm{O}\left(\mathrm{CH}_{2} \mathrm{CH}_{2} \mathrm{O}\right)_{10} \mathrm{H}, \quad 8: \mathrm{R}_{9} \mathrm{C}_{6} \mathrm{H}_{4} \mathrm{O}\left(\mathrm{CH}_{2} \mathrm{CH}_{3} \mathrm{O}\right)_{9.6} \mathrm{H}$,

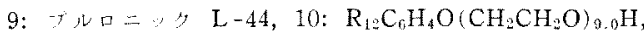
11: $\mathrm{R}_{9} \mathrm{C}_{6} \mathrm{H}_{4} \mathrm{O}\left(\mathrm{CH}_{2} \mathrm{CH}_{2} \mathrm{O}\right)_{7,4} \mathrm{H}, 12: 7 \%$ 口

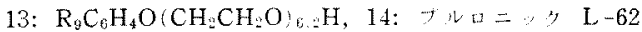

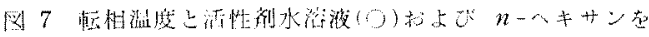

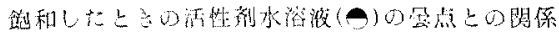

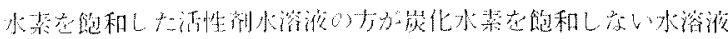

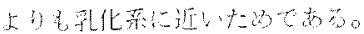

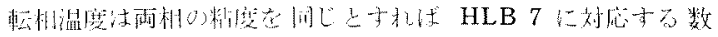

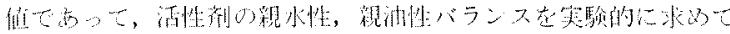
W

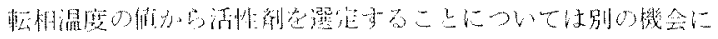
赫车小女。

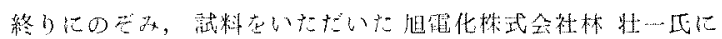

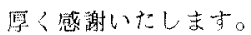

(1964 年 4 月，日本化学全策 17 年会(一部)講㴼) 